\title{
The Proangiogenic Roles of Long Non- Coding RNAs Revealed by RNA-Sequencing Following Oxygen-Glucose Deprivation/Re- Oxygenation
}

\author{
Chengya Wang Youyang Qu Di Wang Yulan Zhu \\ Second Affiliated Hospital of Harbin Medical University, Department of Neurology, Harbin, China
}

\section{Key Words}

Angiogenesis • Endothelial cells • Long non-coding RNAs • Oxygen-glucose deprivation/reoxygenation - Pseudogenes $\cdot$ RNA-sequencing

\begin{abstract}
Background/Aims: With advances in RNA-sequencing (RNA-seq), exploring the expression and transcripts of different classes of genes are now possible. Our purpose was to analyse to the long non-coding RNAs (IncRNAs) in mouse brain microvascular endothelial cells (bEnd.3) after oxygen-glucose deprivation/re-oxygenation (OGD/R). Methods: RNA-seq was employed to explore the expression of IncRNAs, and quantitative real-time PCR (qRT-PCR) was used to identify the results of RNA-seq. Furthermore, the biological functions of the IncRNAs were identified by cell viability, wound healing, transwell, tube formation and immunofluorescent staining assays. Finally, the molecular mechanisms involving the differentially expressed IncRNAs were further explored by bioinformatics and Western blotting (WB). Results: In total, 2710 IncRNAs were found, 33 of which were significantly differentially expressed, with 18 upregulated IncRNAs and 15 downregulated IncRNAs in brain microvascular endothelial cells following OGD/R. Among the dysregulated genes, $G$ protein-coupled receptor 137b-pseudogene (Gpr137b-ps), predicted gene 32856 (Gm32856), small nucleolar RNA host gene 17 (snhg17), chaperonin containing Tcp1 and subunit 6a (Cct6a) were significantly upregulated IncRNAs; this finding was further validated using qRT-PCR. Moreover, Gene Ontology (GO) and Kyoto Encyclopaedia of Genes (KEGG) pathway analyses were employed to decipher the potential target genes and signaling pathways of the differentially expressed IncRNAs. Finally, we selected pseudogene-expressed IncRNA Gpr137b-ps as a candidate gene, and report for the first time that pseudogenes can mediate angiogenesis and their potential target genes, namely, 15-lipoxygenase1 (15-LOX1), Signal Transducer and Activator of Transcription 3 (STAT3) and vascular endothelial growth factor (VEGF). Conclusion: Therefore, our study revealed that Gpr137b-ps plays critical roles in the process of angiogenesis,
\end{abstract}




\section{Cellular Physiology Cell Physiol Biochem 2019;52:708-727 \\ \begin{tabular}{ll|l} 
and Biochemistry $\begin{array}{l}\text { DOl: 10.33594/000000050 } \\
\text { Published online: 29 March 2019 }\end{array}$ & $\begin{array}{l}\text { O } 2019 \text { The Author(s). Published by } \\
\text { Cell Physiol Biochem Press GmbH\&Co. KG }\end{array}$ \\
\cline { 2 - 3 } &
\end{tabular} \\ Wang et al.: The Proaniogenic Roles of IncRNAs}

suggesting avenues for the development of future therapeutic strategies that contribute to promoting angiogenesis following $\mathrm{I} / \mathrm{R}$.

\section{Introduction}

Despite advances in clinical and pharmacological interventions, stroke continues to be the second leading cause of mortality worldwide and a major cause of permanent disability in adults in most countries [1]. Increasing numbers of studies have demonstrated that angiogenesis is vital to the post-ischemia response and recovery following stroke [2]. Therefore, therapeutic angiogenesis is a promising strategy for augmenting vessel regeneration in ischemic tissues and organs [3]. However, the molecular and cellular mechanisms responsible for angiogenesis following stroke are complex and are not fully understood. Therefore, proangiogenic therapy promoting the recovery of the ischemic brain is still a substantial clinical challenge [4]. Thus, we continue to explore the complex mechanisms of stroke development and seek to discover novel therapeutic strategies for the promotion of cerebrovascular endothelial cell proliferation and differentiation and the formation of vascular nodules [5], which may facilitate angiogenesis and the recovery following cerebral ischemic injury.

With the emergence of high-throughput sequencing technologies, it has been found that greater than $98 \%$ of the mammalian genome transcribes into non-coding RNAs (ncRNAs) [6]. Among these non-coding segments are genomic loci called pseudogenes, which are a subclass of IncRNAs that have arisen from protein-coding genes [7]. It has been reported that pseudogenes have more than $90 \%$ sequence homology with protein-coding genes located on different chromosomes [8]. Although pseudogenes were considered nonfunctional genomic fossils when they were discovered in 1977 [9], recently, increasing numbers of studies have shown multilayered biological functions of some pseudogenes in multiple cellular processes [10], especially in human diseases, including the development and progression of cancer [11-14]. For instance, the pseudogene-expressed lncRNAs SUM01P3 and POU5F1B were reported to be amplified and expressed at high levels in gastric cancer, and their expression levels are significantly associated with cell differentiation, proliferation, migration and invasion [15-17]. However, no attempts to determine whether pseudogenes exert any effects on angiogenesis after stroke have been reported.

In this study, Gpr137b-ps was found for the first time to be a pseudogene-expressed IncRNA. It is aberrantly expressed in mouse brain microvascular ECs after OGD/R, and transfection with Gpr137b-ps resulted in reduced cell proliferation, migration, tube formation and microvessel density. Therefore, our novel results indicate that pseudogenes are significantly upregulated in ECs after OGD/R treatment, and show that the upregulation of Gpr137b-ps mainly acts on ECs to promote angiogenesis in vitro.

\section{Materials and Methods}

\section{Experimental protocol}

Cultured mice brain microvascular endothelial cells (bEnd.3) were divided into the following two groups: the OGD/R group and the control group. Hypoxia can promote angiogenesis, which was identified by the cell survival, cell migration, transwell, tube formation and immunofluorescent staining assays. Subsequently, six samples ( $n=3$ /group) were used to explore the gene transcripts by RNA-seq. Next, the gene transcripts obtained from RNA-seq were analysed by bioinformatics. Finally, candidate lncRNAs were selected for subsequent studies. The experimental protocol is shown in Fig. 1. 
Brain microvascular endothelial cell cultures

The bEnd.3 cell line was purchased from Cell Bank (Shanghai, China) and incubated in Dulbecco's modified Eagle's medium (Corning, New York, USA) supplemented with $10 \%$ fetal bovine serum (FBS, CellMax, Australia) and antibiotics (100 U/ml penicillin and $100 \mu \mathrm{g} / \mathrm{ml}$ streptomycin) (Beyotime, Beijing, China) at $37{ }^{\circ} \mathrm{C}$ in a humidified incubator with $5 \% \mathrm{CO}_{2}$.

\section{Oxygen-glucose deprivation/ reoxygenation}

To generate a model of cerebral ischemia/reperfusion in vitro, endothelial cells (ECs) were treated with $\mathrm{OGD} / \mathrm{R}$, which is a well-established method of studying the pathological processes of ischemia. First, ECs were rinsed with phosphate buffered saline (PBS, Solarbio, Beijing, China). Then, the ECs were cultured in glucosefree DMEM (Gibco, New York, USA)

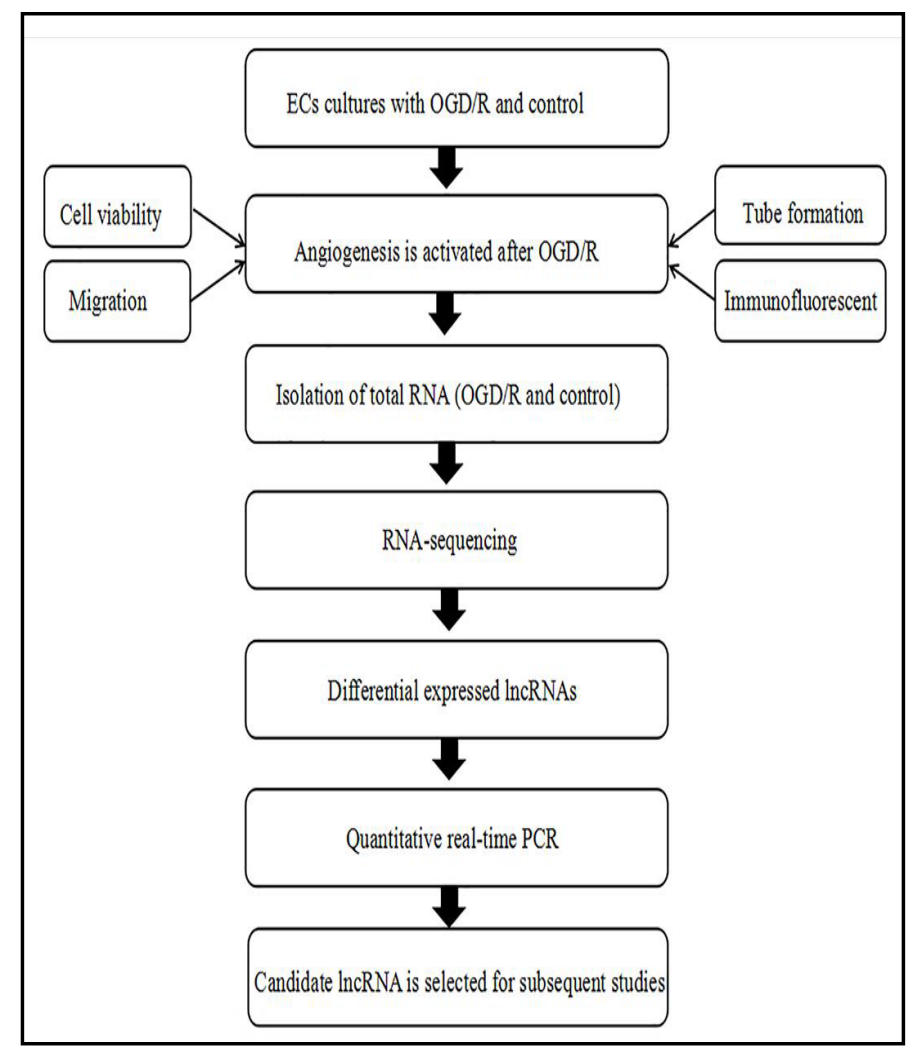

Fig. 1. Summary of experimental protocols. without FBS in a hypoxic incubator $\left(95 \% \mathrm{~N}_{2}, 5 \% \mathrm{CO}_{2}\right)$ at $37{ }^{\circ} \mathrm{C}$ for $10 \mathrm{~h}$. Next, the cells were allowed to re-oxygenate in absolute culture medium under normoxic conditions (95\% air, $\left.5 \% \mathrm{CO}_{2}\right)$ to finish re-oxygenation. Additionally, some ECs were incubated under normoxic conditions and served as the control group. The concentration of $\mathrm{O}_{2}$ was managed by gas monitoring (Smart Sensor, Hong Kong, China).

\section{Cell viability assay}

3-(4, 5-dimethylthiazol-2-yl)-2, 5-diphenyltetrazolium (MTT, Beyotime, Beijing, China) was employed to analyse endothelial cell viability. In total, $1 \times 10^{4}$ cells were incubated in 96 -well plates and added to culture medium with $10 \mu \mathrm{l}$ of $5 \mathrm{mg} / \mathrm{ml}$ MTT reagent at $37{ }^{\circ} \mathrm{C}$ for $4 \mathrm{~h}$ under normal growth conditions. Then, the cells were lysed to dissolve formazan crystals at room temperature by adding $100 \mu \mathrm{l}$ of dimethyl sulfoxide (DMSO, Solarbio, Beijing, China) for $10 \mathrm{~min}$. Finally, the viable cells were quantified by measuring the optical density (OD) values at $490 \mathrm{~nm}$ in a universal enzyme system (Bio-Rad, Shimadzu, Japan). The cell viability= (OD value in $O G D / R$ - OD value in blank)/(OD value in control - OD value in blank) $\times 100 \%$.

\section{Wound healing assay}

A scratch assay was employed to assess the capacity for migration of the ECs after OGD/R. A six-well plate was divided with a marker pen approximately every $0.5-1.0 \mathrm{~cm}$, with at least five lines through every well. In total, $3 \times 10^{5}$ cells per well were incubated in a six-well plate and grown to confluence overnight. Across this confluence monolayer, a single scarification was generated perpendicular to the five lines with a sterile $200-\mu \mathrm{l}$ pipette tip. Then, the medium was refreshed in a $5 \% \mathrm{CO}_{2}, 95 \% \mathrm{~N}_{2} 37{ }^{\circ} \mathrm{C}$ incubator, and normoxic conditions were used as a control. It is worth noting that the medium lacks FBS culture to avoid the influence of cell proliferation. The scratch healing was imaged, and the percent of area the cells occupied was analysed using ImageJ software. 


\section{Cellular Physiology Cell Physiol Biochem 2019;52:708-727 \\ \begin{tabular}{c|c|c|c|c|}
\hline DOI: 10.33594/000000050 & 2019 The Author(s). Published by \\
\hline and Biochemistry &
\end{tabular} \\ \begin{tabular}{ll} 
Published online: 29 March 2019 Cell Physiol Biochem Press GmbH\&Co. KG \\
\hline
\end{tabular} \\ Wang et al.: The Proaniogenic Roles of IncRNAs}

\section{Transwell experiments}

A transwell assay was also performed to analyse the capacity for migration of the ECs after OGD/R using transwells with $8-\mu \mathrm{m}$ porous filters (Corning, NY, USA). In total, $5 \times 10^{4}$ cells that had experienced a hypoxic stimulus were added to the upper chamber with glucose-free DMEM without FBS, and $200 \mu \mathrm{l}$ of absolute medium was added to the lower chamber. After incubation at $37{ }^{\circ} \mathrm{C}$ and $5 \% \mathrm{CO}_{2}$ for $24 \mathrm{~h}$, the migrated cells were visualized on the lower surface of the membrane by staining with crystal violet and counted (Sigma, China). The average number of migrated cells in different fields is presented in a bar diagram (10× magnification).

\section{Tube formation assay}

The capillary network formation ability of brain microvascular ECs was analysed by a tube formation assay following OGD/R. Matrigel (BD, New York, USA) was prepared at $4{ }^{\circ} \mathrm{C}$ overnight, and $30 \mu \mathrm{l}$ of Matrigel was used to coat a 96-well plate. The Matrigel was allowed to solidify for $60 \mathrm{~min}$ at $37^{\circ} \mathrm{C}$, and then ECs that had undergone an OGD/R treatment or a control treatment were added to the 96 -well plate at $1-1.5 \times 10^{4}$ cells per well in culture medium with 5\% FBS. The numbers of tube loops in the capillary network were counted to estimate in vitro angiogenesis. The mean number of tube loops from five visual fields are represented in a bar diagram $(\times 100)$.

\section{Immunofluorescent staining analysis}

Cultured bEnd. 3 cells subjected to OGD/R or the control treatment were fixed with $4 \%$ paraformaldyde for $20 \mathrm{~min}$ and then incubated with 1\% TritionX-100 solution (Solarbio, Beijing, China) for $10 \mathrm{~min}$. Then, the cells were rinsed with PBS for $5 \mathrm{~min}$. The cells were incubated with goat serum at $37^{\circ} \mathrm{C}$ for $60 \mathrm{~min}$ to block nonspecific binding sites. Anti-CD31 primary antibody solution (1:100, ab222785, Abcam, Cambridge, MA, USA) was added to the cells, and they were incubated at $4{ }^{\circ} \mathrm{C}$ overnight. Each section was washed with PBST (PBS with $0.05 \%$ Tween 20) for 5 min and incubated with Cy3 goat anti-rabbit IgG $(\mathrm{H}+\mathrm{L})$ secondary antibody (1:100, ABclone, Boston, USA) at $37^{\circ} \mathrm{C}$ for $2 \mathrm{~h}$ the following day. PBS was used instead of the primary antibody as a control to confirm the specificity of the antibody. Anti-fade DAPI solution was added to the plate. The cells were imaged using a confocal microscope (Nikon, Tokyo, Japan). Finally, the images were analysed using ImageJ software and analysed with Photoshop.

\section{Library preparation and RNA sequencing}

In total, $3 \mu \mathrm{g}$ of RNA per sample was used as input material for the RNA sample preparation. First, ribosomal RNA (rRNA) was removed with an Epicentre Ribo-zero kit (Epicentre, Madison, USA). Subsequently, the rRNA-depleted RNA was prepared to generate sequencing libraries by the Illumina system (NEB, Ipswich, USA). The library quality was assessed on the Agilent Bioanalyzer 2100 system. The sequenced reads were 150-200 bp and were mapped using TopHat, with 2 mismatches allowed. The index of the reference genome was built using bowtie2 (v2.2.28), and paired-end clean reads were aligned to the reference genome using HISAT2 (v2.0.4) [18]. FPKM distribution values were calculated for the expression levels of each transcript by Cuffdiff (v2.1.1) [19]. Biological repetition is necessary for technique, and highthroughput sequencing technology is no exception [20]. The reliability and reasonability of the results were evaluated by Pearson's correlation. The Pearson's correlation value determined for each pair of replicates needed to be at least 0.8 .

\section{Coding potential analysis and conservative analysis}

Currently, there are four tools for coding potential analysis, including the Coding-Non-Coding-Index (CNCI) (v2), the Coding Potential Calculator (CPC) (0.9-r2), Pfam Scan (v1.3) and phylogenetic codon substitution frequency (PhyloCSF) (v20121028) [21-24]. In our study, transcripts with coding potential that conformed to either/all of the above four tools were removed, and the remaining transcripts without coding potential were selected as our candidate set of IncRNAs. 
Differential expression analysis

Cuffdiff (v2.1.1) was used to calculate the number of fragments per kilobase million (FPKMs) of both the IncRNAs and the coding genes in each sample. Gene FPKMs were computed by summing the FPKMs of the transcripts in each group [25]. Statistical analyses are provided by Cuffdiff to determine differential expression in digital transcript or gene expression data using a model based on the negative binomial distribution [25]. A P-adjusted $<0.05$ for transcripts or genes indicated differential expression.

\section{GO and KEGG enrichment analysis}

Gene Ontology (GO) enrichment analysis was performed to elucidate the biological implications of the differentially expressed genes. Additionally, differentially expressed genes or their target genes were evaluated by the GOseq R package, in which the gene length bias was corrected [26]. GO terms with corrected $p$ values less than 0.05 were considered significantly enriched in the differentially expressed genes. The Kyoto Encyclopedia of Genes and Genomes (KEGG) is a database resource for understanding high-level functions and utilities of the biological system [27], such as the cell, the organism and the ecosystem, from molecular information, especially large-scale molecular datasets generated by genome sequencing and other high-throughput experimental technologies (http://www.genome.jp/kegg/). The KEGG database was also used to determine the significant pathways involving the differentially expressed genes (DEGs). Finally, we used KOBAS software to test the statistical enrichment of differentially expressed genes or IncRNA target genes in the KEGG pathways [28].

\section{PPI analysis}

Protein-protein interaction (PPI) analysis of DEGs was conducted with the STRING database, which contains the known and predicted PPIs. The networks of the related genes were constructed using Cytoscape (version 3.5.1). In each network, the circular nodes represented significantly expressed mRNAs; the black lines showed the PPIs.

\section{Quantitative real-time polymerase chain reaction analysis}

Total RNA was extracted from different groups using the TRIzol reagent (Invitrogen, California, USA) according to the manufacturer's instructions. Reverse transcription was performed with a cDNA Reverse Transcription kit (Roche, Indianapolis, USA). Subsequently, the reverse transcription products were quantified using FastStart SYBR Green PCR Master Mix (Roche, Indianapolis, USA) in a 10- $\mu$ l reaction volume with a Bio-Rad CFX96 Detection System (Bio-Rad, Shimadzu, Japan). Each sample was run in triplicate, and the analysis of the relative gene expression level was performed with $\beta$-actin as the reference using the $2^{-\Delta \Delta C T}$ method. The sequences of the specific primers used in our experiment are shown in Table 1.

Table 1. Sequences of primers

\begin{tabular}{|c|c|c|}
\hline Name of primers & Sequences(5' to $\left.3^{\prime}\right)$ & Amplified products \\
\hline Gpr137b-ps & $\begin{array}{l}\text { Forward: GGCAAGGTCATCATCACTGTCATAT } \\
\text { Reverse: GTTTGGCGTGGTGCTTTTCGT }\end{array}$ & $181 \mathrm{bp}$ \\
\hline Dleu2 & $\begin{array}{l}\text { Forward: TAAATGTCAGTCGGTGTAGCG } \\
\text { Reverse: CAGGCAGACAGAATGGATAAC }\end{array}$ & $143 \mathrm{bp}$ \\
\hline Gm32856 & $\begin{array}{l}\text { Forward: GTTGGTCATCCATCGGTCAGG } \\
\text { Reverse: TCTCCAGGGAGGAAGAGG }\end{array}$ & $162 \mathrm{bp}$ \\
\hline Snhg17 & $\begin{array}{l}\text { Forward: GCATACCCTCGTTCCTGTCTA } \\
\text { Reverse: ATGATTTTAGGGCTTGTGAGA }\end{array}$ & $220 \mathrm{bp}$ \\
\hline Cct6a & $\begin{array}{l}\text { Forward: TCCCAAACAGTCAGGATTCAGGT } \\
\text { Reverse: TGCGAAAGAAGGGATCGTAGC }\end{array}$ & $121 \mathrm{bp}$ \\
\hline Briplos & $\begin{array}{l}\text { Forward: CAAGACTGAACTTTTCCCACA } \\
\text { Reverse: AATTATCAACAGCACCAACCC }\end{array}$ & $207 \mathrm{bp}$ \\
\hline$\beta$-actin & $\begin{array}{l}\text { Forward: GGGAAATCGTGCGTGAC } \\
\text { Reverse: AGGCTGGAAAAGAGCCCT }\end{array}$ & $176 b p$ \\
\hline
\end{tabular}




\section{Cellular Physiology Cell Physiol Biochem 2019;52:708-727 \\ \begin{tabular}{c|c|c|c|}
\hline DOI: 10.33594/000000050 & 2019 The Author(s). Published by \\
\hline and Biochemistry
\end{tabular} \\ \begin{tabular}{ll} 
Published online: 29 March 2019 Cell Physiol Biochem Press GmbH\&Co. KG \\
\hline
\end{tabular} \\ Wang et al.: The Proaniogenic Roles of IncRNAs}

\section{The model of middle cerebral artery occlusion}

Mice were anesthetized with $1.5 \%$ isoflurane in 30\% oxygen with a face mask. A 2-cm length of 7-0 rounded silicone-rubber-coated monofilament (L3600, Jialing, Guangzhou, China) was introduced into the right middle cerebral artery [29]. Sham group animals were subjected to similar operations, exposing the internal carotid artery without the occlusion of the middle cerebral artery. After $60 \mathrm{~min}$, the filament was removed to allow reperfusion for $48 \mathrm{~h}$. The animal experiments were performed in compliance with Animal Research: Reporting in vivo Experiments (ARRIVE) guidelines.

\section{Cell transfection}

To generate a lentivirus expressing shGpr137b-ps and a non-targeting Gpr137b-ps shRNA, brain microvascular endothelial cells were cultured in a 6-well plate for $12 \mathrm{~h}$. Then, the culture medium was centrifuged to collect the lentiviruses. The obtained viral supernatant was added to a new culture plate that was incubated with fresh culture medium as well as $1 \mu \mathrm{l}$ of polybrene. Importantly, the new culture dish contained cells at no more than $60 \%$ confluence. The culture medium was changed on the following day. After $48 \mathrm{~h}$ of culturing, the cells were screened with puromycin (Thermo Fisher, Shanghai, China) through the observation of fluorescence intensity. The cells were harvested: some were frozen and the rest were used for the subsequent experiments.

\section{Western blotting analysis}

Cells were homogenized in lysis buffers (Solarbio, Beijing, China) with a phosphorylation inhibitor (Roche, Indianapolis, USA). The total protein concentration of each sample was measured with a bicinchoninic acid (BCA) kit (Beyotime, Shanghai, China). Equivalent amounts of protein were separated via $8 \%-10 \%$ SDS polyacrylamide gel electrophoresis (SDS-PAGE), and the resolved protein bands were transferred onto a pretreated polyvinylidene fluoride (PVDF, Thermo Fisher, Shanghai, China) membrane. The PVDF membranes were incubated with specific primary antibodies $(1: 1000)$ at $4{ }^{\circ} \mathrm{C}$ overnight after blocking in skim milk. Following incubation, the membranes were then washed and incubated with goat anti-rabbit IgG and goat anti-mouse IgG secondary antibodies (diluted at 1:5000, ABclone, Boston, USA) at room temperature for $1 \mathrm{~h}$. Finally, the immunoreactive bands were detected using an enhanced chemiluminescence reagent (ECL) kit (Vazyme, Nanjing, China). The band intensity of each band area was quantified using ImageJ.

\section{Statistical Analysis}

All data are expressed as the mean \pm standard error (SEM). Student's unpaired t-test or one-way ANOVA was used for all pairwise comparisons. The statistical analysis was performed with GraphPad Prism version 5.5 for Windows (GraphPad Software, San Diego, CA, USA). A $p$-value less than 0.05 was considered statistically significant $\left({ }^{*} p<0.05,{ }^{* *} p<0.01,{ }^{* * *} p<0.001\right)$.

\section{Results}

\section{OGD/R stimulation can promote EC proliferation, migration, and tube formation and} increased microvessel density

Mice brain microvascular endothelial cells were cultured to confluence and then subjected to OGD for $10 \mathrm{~h}$. Subsequently, the cells were cultured with re-oxygenation for $48 \mathrm{~h}$. The results revealed that compared with the control treatment, hypoxic insults could induce a highly significant increase in endothelial cell survival as revealed by the MTT analysis (Fig. 2A). Moreover, the functional analyses of ECs following OGD/R, including the migration assay (Fig. 2B, 2C), transwell (Fig. 2D and 2E), tube formation assay (Fig. 2F and $2 \mathrm{G}$ ) and CD31 positive microvascular endothelial cell count by immunofluorescence (Fig. $2 \mathrm{H}$ and $2 \mathrm{I}$ ), were also significantly greater following OGD/R than the control treatment. 


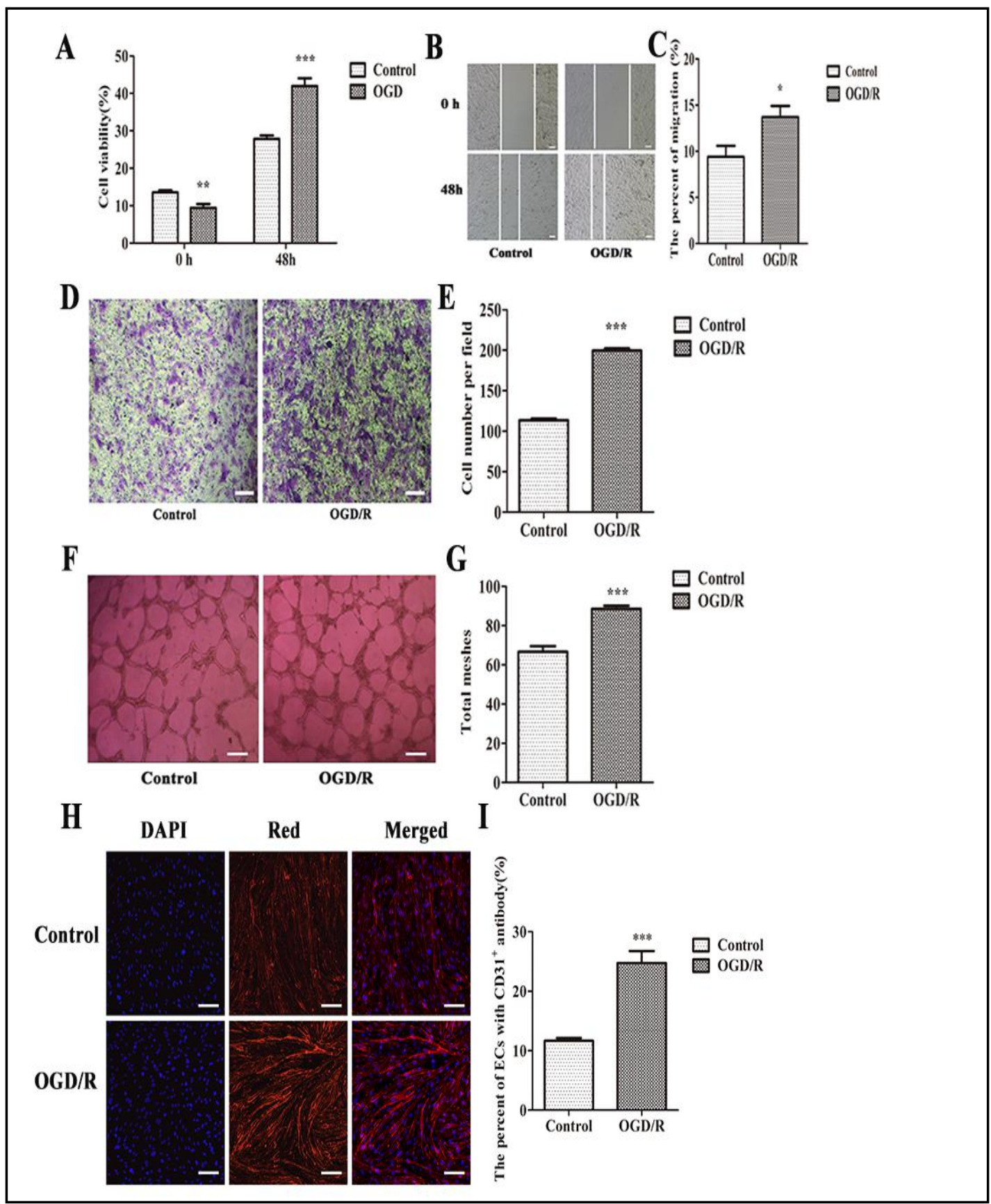

Fig. 2. The survival rate, migration and neovascularization of brain microvascular endothelial cells in the OGD/R group and control group. (A) Cell viability was higher in the control group than in the OGD/R group at $0 \mathrm{~h}$; after $48 \mathrm{~h}$ of re-oxygenation, cell viability was higher in the OGD/R group than in the control group ( ${ }^{\mathrm{p}} \mathrm{p}<0.05$ vs. control). (B) Scratch-wound assay in OGD/R cells compared with control endothelial cells; (C) Statistical analysis of the difference in migration capacity between the OGD/R and control groups $\left({ }^{*} \mathrm{p}<0.05\right.$ vs. control). (D) Representative images of transwells in the control group and OGD/R group; (E) Statistical analysis of the number of migrated cells in the two groups. ( ${ }^{*} p<0.05$ vs. control). (F) Tube formation assay in the OGD/R group and control group; (G) Statistical analysis of the number of meshes from two groups (* $\mathrm{p}<0.05$, ** $\mathrm{p}<0.01$, *** $\mathrm{p}<0.001$ vs. control). (H) Representative immunofluorescence staining of the control and OGD/R groups revealed by laser confocal microscopy, scale bar $=50 \mu \mathrm{m}$. (I) Statistical analysis comparing angiogenesis between the control and OGD/R groups $\left(^{*} \mathrm{p}<0.05,{ }^{* *} \mathrm{p}<0.01,{ }^{* * *} \mathrm{p}<0.001\right.$ vs. control). All results are presented as the mean \pm SEM. 


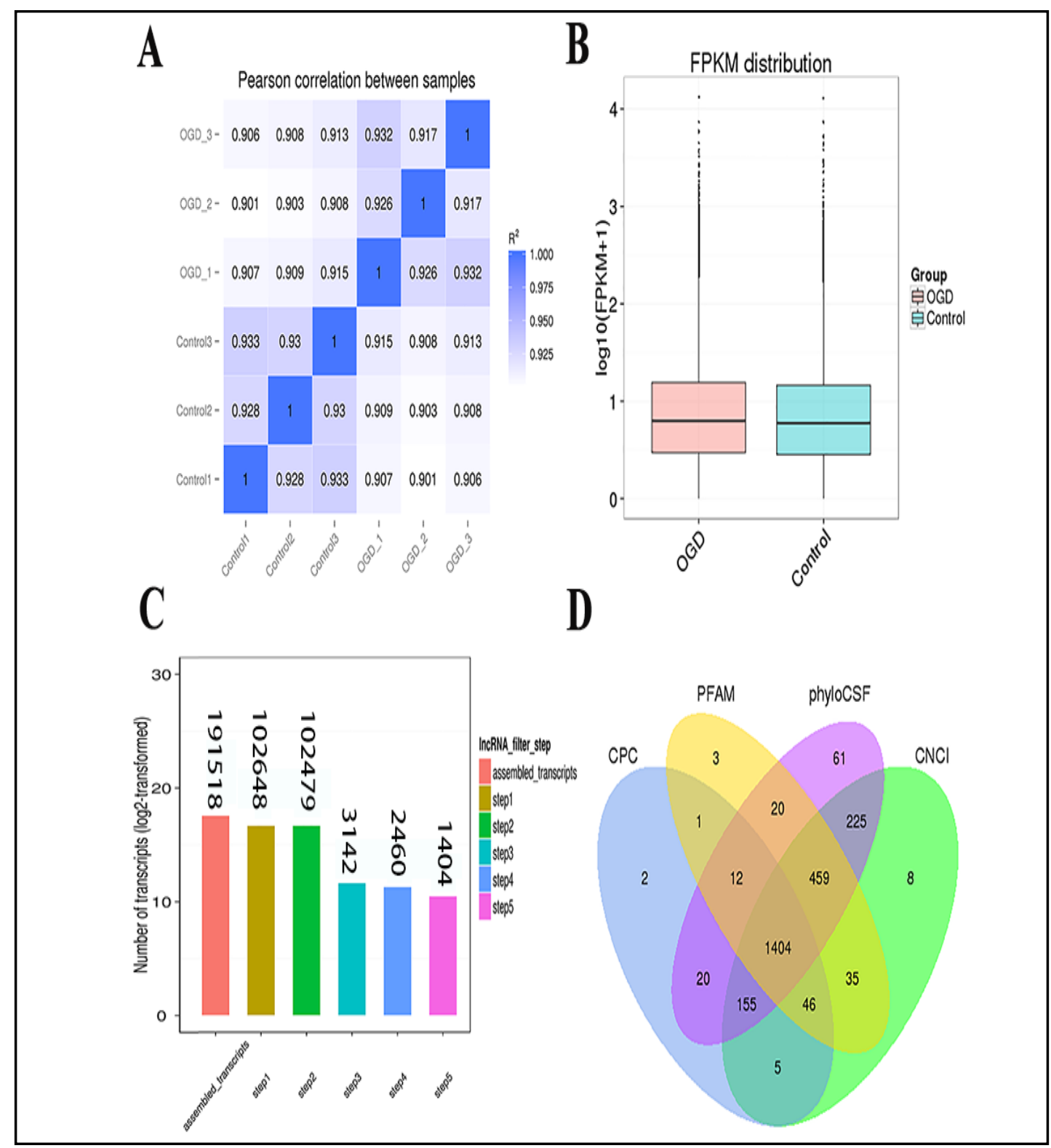

Fig. 3. The evaluation of samples and filtration of lncRNAs. (A) Pearson's correlation coefficient was more than 0.8 for each pair. (B) The box plots of FPKM distribution in each group, indicating no significant differences between the control and OGD/R groups. (C) The transcripts from five steps of filtration are shown. (D) The results regarding the non-coding RNAs exhibited in a Venn diagram. The sum of the numbers in each large circle represents the total number of non-coding transcripts identified by the particular software, and the overlapping part of the circle represents the common non-coding transcripts between the different types of software.

\section{Identification of IncRNA transcriptomes in brain microvascular endothelial cells after $O G D / R$}

To determine the IncRNA transcriptomes in brain microvascular ECs treated with OGD/R and the control, we used RNA-seq technology on total RNA extracted from the control and OGD/R with three independent biological samples per group. In total, $85.68 \%$ of the generated reads from RNA-seq were mapped to the mouse reference genome. Before the IncRNA transcriptome data were analysed, the reliability and reasonability of the samples were tested by Pearson's correlation. Pearson's correlation value was more than 0.8 for each 
Table 2. Classification of transcriptome

\begin{tabular}{lcc}
\hline Transcriptome & Classification & Number \\
\hline ncRNAs & Total & 59067 \\
LncRNAs & Total & 2710 \\
& Annotated & 1306 \\
& Non-annotated & 1404 \\
mRNAs & Differentially expressed & 33 \\
\hline
\end{tabular}

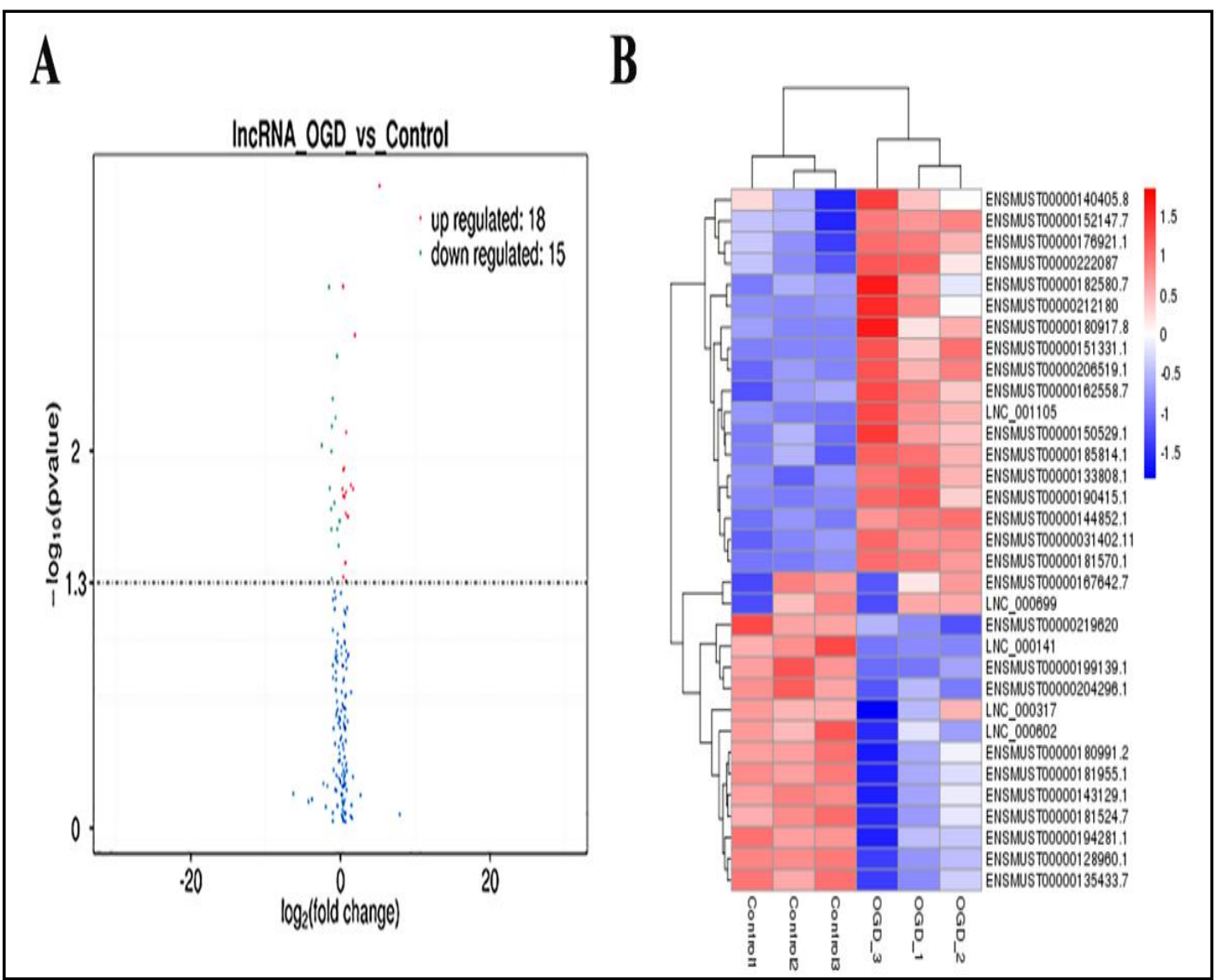

Fig. 4. Differentially expressed IncRNAs were exhibited by volcanoplot and clustering analysis. (A) A volcano plot of the differentially expressed lncRNAs between the control and OGD/R groups. (B) Heatmap and hierarchical clustering analyses of the 33 differentially expressed lncRNAs. The expression values are represented in shades of red and blue, indicating expression above and below the median value, respectively, across all samples.

pair (Fig. 3A). Furthermore, differences were not found in the FPKM values of each sample (Fig. 3B). Subsequently, the filtration of IncRNAs conformed to a series of criteria based on the analysis of cufflinks and scripture according to the characteristics of the lncRNAs. The numbers of transcripts after five steps of filtration are shown (Fig. 3C), and the fifth step was the coding potential analysis, which was conducted with four common tools, namely the CNCI, CPC, Pfam Scan and PhyloCSF. The transcripts with coding potential were eliminated by any or all of the four tools, and remaining non-coding transcripts were selected as potential lncRNAs, as exhibited in the Venn diagram (Fig. 3D). The sum of the numbers in each large circle represents the total number of non-coding transcripts identified by the software, and 
the overlapping part of the circle represents the common non-coding transcripts between the different types of software.

In this study, 59067 transcripts were identified, and these transcripts were divided into protein-coding and non-coding RNAs by the protein-coding potential tools. Among them, 55301 were identified as protein-coding transcripts, and 2710 were identified as lncRNAs with limited protein-coding potential. Moreover, among the $2710 \operatorname{lncRNAs}, 1306$ were identified as annotated IncRNAs, and 1404 were classified as novel lncRNAs (Table 2). Significantly differentially expressed lncRNAs were analysed by Cuffdiff bioinformatics analysis. Finally, we found that 33 significantly differentially expressed lncRNAs, with 18 upregulated lncRNAs (17 annotated and 1 non-annotated) and 15 downregulated lncRNAs (11 annotated and 4 non-annotated), as shown by the volcanoplot (Fig. 4A). The most highly upregulated annotated IncRNAs were Gpr137b-ps, Gm32856, Cct6a and snhg17. The most highly downregulated annotated lncRNAs were Brioplos and Gm42890. These differentially expressed lncRNAs were identified by hierarchical clustering analysis (Fig. 4B).

\section{Validation of differentially expressed IncRNAs in brain microvascular endothelial cells}

following $O G D / R$

To verify the findings of the RNA-seq, we randomly selected six lncRNAs and validated their expression at the transcript level with qRT-PCR. We found that the expression levels of four of the six lncRNAs, namely, Gpr137b-ps, Gm32856, snhg17 and Cct6a, were consistent with the results of the RNA-seq (Fig. 5A, 5B, 5C, 5D). Therefore, our findings indicated that OGD/R-responsive IncRNAs may act as potential mediators of angiogenic responses to cerebral ischemic stroke. However, among these differentially expressed genes, pseudogenederived lncRNAs have never been shown to be associated with post-stroke angiogenesis. Therefore, we concentrated on the functional role of Gpr137b-ps in brain microvascular endothelial cells after OGD/R.

\section{Gpr137b-ps as a candidate gene}

Gpr137b-ps was identified as a pseudogene-derived lncRNA that belongs to non-coding RNAs according to the Ensembl website (Supplementary Fig. S1 - all supplementary material available online at www.cellphysiolbiochem.com). In this study, we discovered increased levels of pseudogene-derived lncRNA Gpr137b-ps in ECs with pro-angiogenic capacity after OGD/R (Fig. 5A). Therefore, our study is the first to demonstrate that Gpr137b-ps is upregulated in response to hypoxia, indicating that Gpr137b-ps may play a pro-angiogenic role.

Gpr137b-ps enhances EC proliferation, migration, tube formation and microvessel density following $O G D / R$

To assess the correlation between Gpr137b-ps expression and angiogenesis, knockdown with a lentiviral vector resulted in lower levels of Gpr137b-ps. shGpr137b-ps-1 showed a significant reduction of Gpr137b-ps mRNA (Fig. 5E); however, the mRNA levels of Gpr137bps in shGpr137b-ps-2 and shGpr137b-ps-3 were not significantly different from those in the non-targeting Gpr137b-ps shRNA group (Fig. 5E). Next, cell survival, cell migration and vascular nodule formation were analysed using MTT, transwell, scratch and tube formation assays. We found that the transfection of Gpr137b-ps significantly impeded cell viability (Fig. 6A), migration (Fig. 6B-6E) and vascular nodule formation compared with the results of transfection with non-targeting Gpr137b-ps shRNA after OGD/R treatment (Fig. 6F, 6G). Furthermore, the number of CD31-positive microvascular endothelial cells was reduced by the knockdown of Gpr137b-ps (Fig. 6H, 6I). 
Fig. 5. The validation of differentially expressed lncRNAs. (A-D) The upregulation of the relative mRNA expression of Gpr137b-ps, Gm32856, Snhg17 and Cct6a caused by OGD/R. ( ${ }^{* *} \mathrm{p}<0.01$, *** $\mathrm{p}<0.001$ vs. control). (E) Lentiviral transfection with interference sequence 1 targeting Gpr137b-ps reduced the relative mRNA expression of Gpr137b-ps, and lentiviral transfection with interference sequences 2 and 3 targeting Gpr137b-ps did not reduce the relative mRNA expression of Gpr137b-ps (* p <0.05, ** $\mathrm{p}<0.01$, *** $\mathrm{p}<0.001$ vs. non-targeting Gpr137bps shRNA). All results are presented as the mean \pm SEM.

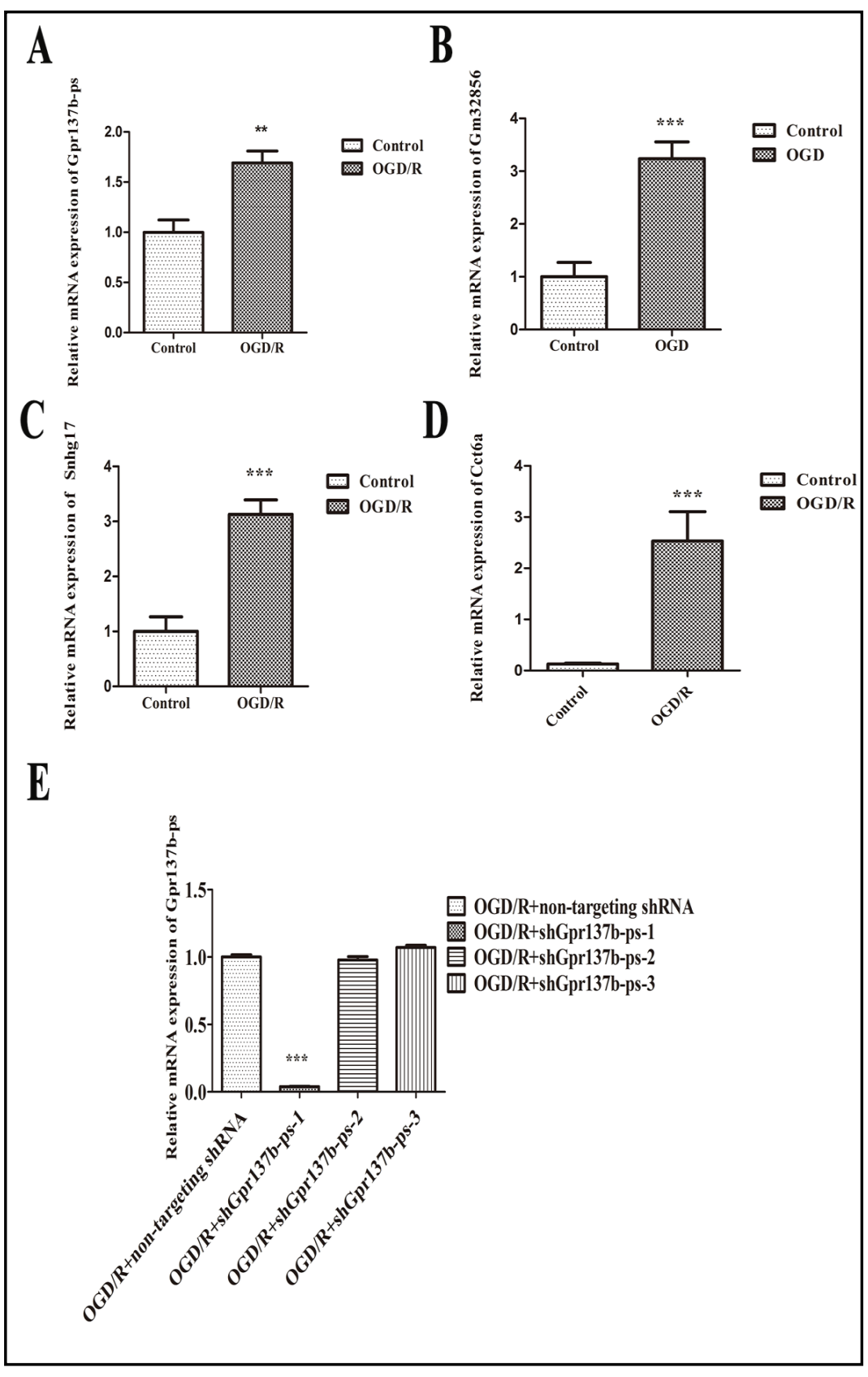

Potential functional enrichment and biological pathway analysis

To identify the functions of the differentially expressed lncRNAs, GO analysis, including cellular components (CC), biological processes (BP) and molecular functions (MF) was conducted (Supplementary Fig. S2), and most of the highly expressed GO terms were associated with cell metabolism and the response to stress. Additionally, the results of the KEGG pathway analysis included the upregulated (Fig. 7A) and downregulated pathways (Fig. 7B). Among the upregulated pathways, the phosphoinositide 3-kinase-Akt (PI3K-Akt), Janus Kinase-Signal Transducer and Activator of Transcription (Jak-STAT) and Adenosine 5 '-monophosphate (AMP)-activated protein kinase (AMPK) signaling pathways were the most enriched. 
Fig. 6. The functions of endothelial cells was mediated by the knockdown of Gpr137bps in response to OGD/R. (A) Knockdown of Gpr137b-ps reduced the viability of endothelial cells after OGD/R. (BE) Knockdown of Gpr137b-ps reduced the capacity for migration of endothelial cells after OGD/R according to the scratch-wound and transwell assays. (F) Knockdown of Gpr137b-ps reduced the number of loops of endothelial cells after $\mathrm{OGD} / \mathrm{R}$ according to the tube formation assay. (G) Statistical analysis of the capacity for migration in cells treated with shGpr137b-ps compared with a nontargeting Gpr137b-ps shRNA $\left(^{*} \mathrm{p}<0.05, * *\right.$ $\mathrm{p}<0.01,{ }^{* * *} \mathrm{p}<0.001$ vs. non-targeting Gpr137b-ps shRNA). (H) Transfection with Gpr137b-ps prevented the elevation of CD31 levels in endothelial

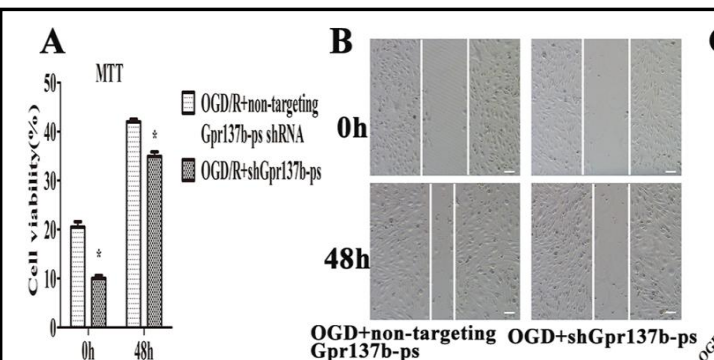

C$$
\text { D }
$$

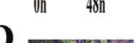

OGD+non-ta
Gpr137b-ps
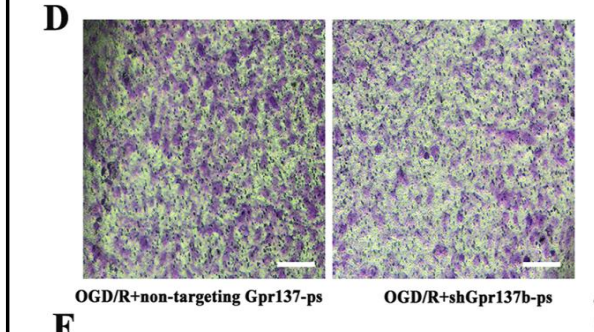

$$
\mathbf{F}^{\text {oc }}
$$
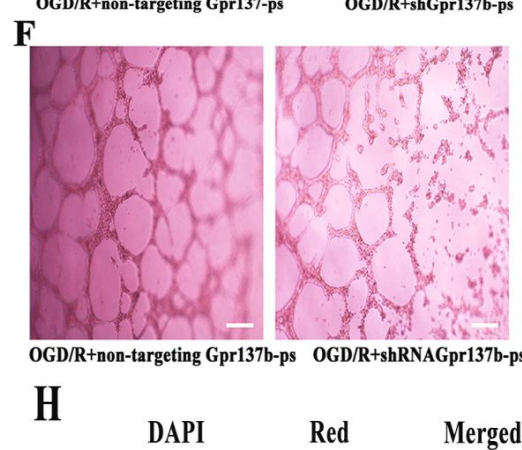

H

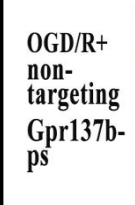
OGD/Rt+
shGpr137
$-\mathrm{ps}$ E $\quad$ 口 OGD $\boldsymbol{R}^{+ \text {non-targeting }}$

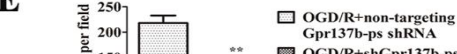
(1) $\stackrel{\mathbf{G}}{ }$ $\square 0$
$\begin{aligned} & \text { OGD/R+non-targeting } \\ & \text { Gpr137b-ps shRNA }\end{aligned}$
OGD/R+shGpr137b-ps $-2$

\section{DAPI}

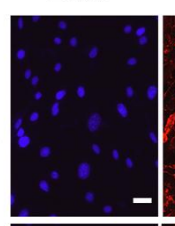

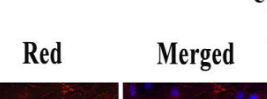
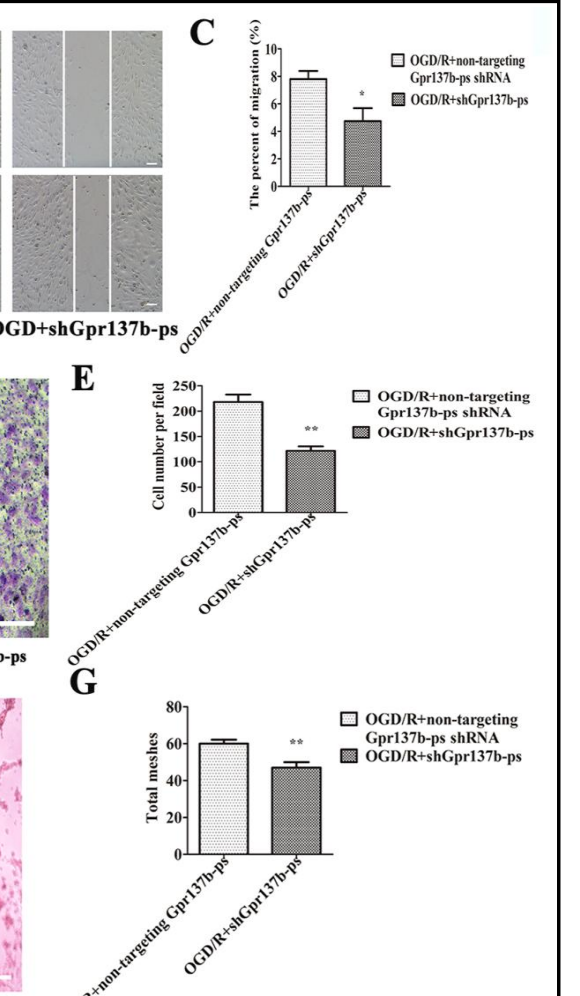

cells after OGD/R. (I)

Summary graph depicting the CD31 signal intensity, which was significantly decreased after treatment with shGpr137b-ps compared with treatment with a non-targeting shRNA. $\left({ }^{*} \mathrm{p}<0.05,{ }^{* *} \mathrm{p}<0.01\right.$, ${ }^{* * *} \mathrm{p}<0.001 \mathrm{vs}$. non-targeting Gpr137b-ps shRNA). All results are presented as the mean \pm SEM.

\section{Regulation of the expression of STAT3 and VEGF by Gpr137b-ps}

To further decipher the potential mechanisms underlying the mediation of EC proliferation, migration, tube formation and neovascularization by Gpr137b-ps following OGD/R, we screened potential target genes of Gpr137b-ps according to the results of the IncRNA_mRNA_co_expression analysis. Among these targets, signal transducer and activator transcription 3 (STAT3) and vascular endothelial growth factor (VEGF) were the common factors associated with angiogenesis. To validate the computational prediction results, western blotting was used to determine the expression of VEGF and phosphorylation of signal transducer and activator transcription 3 (pSTAT3) in vitro. As shown in Fig. 8A-8D, we 

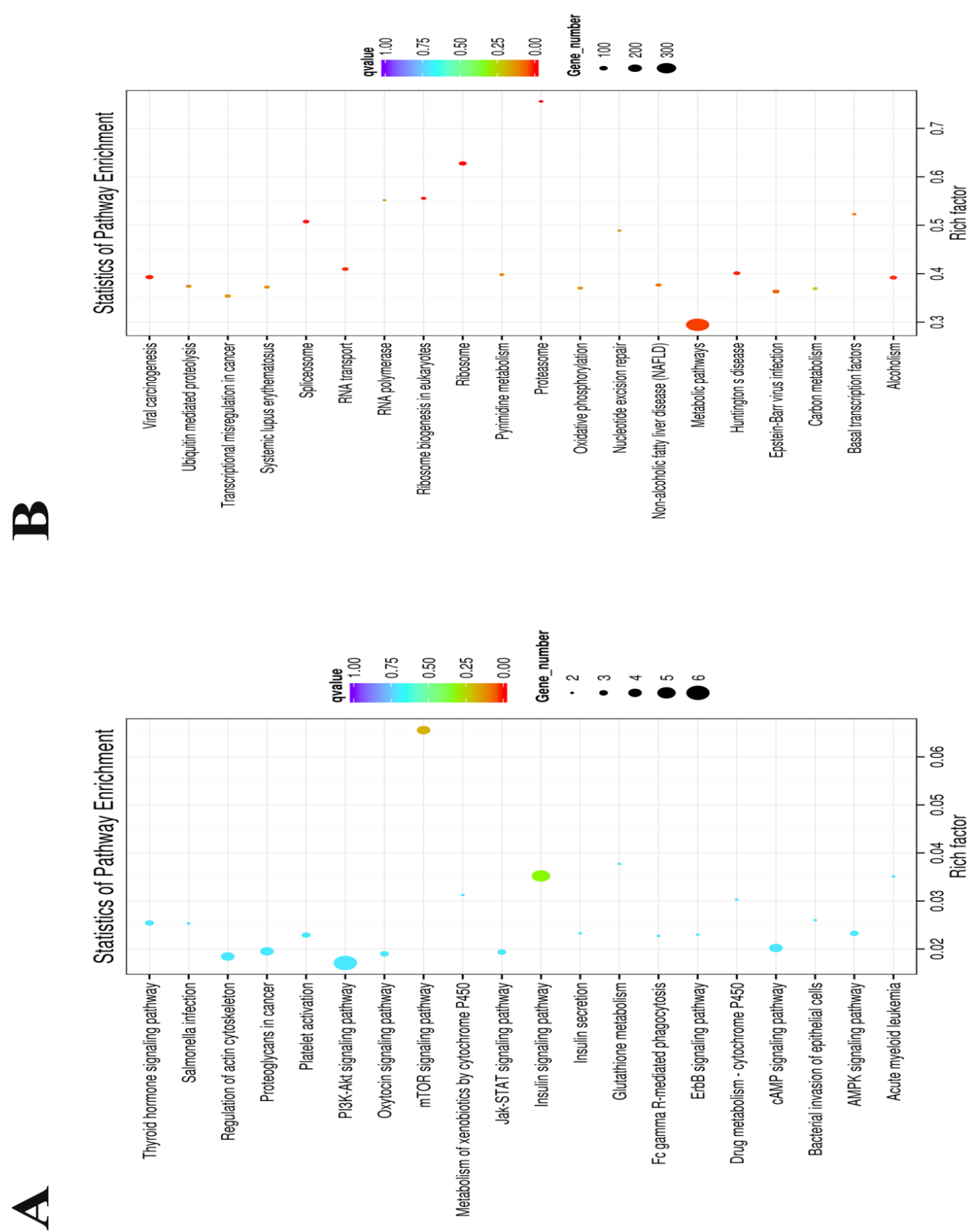

Fig. 7. KEGG analysis. (A and B) The potential signaling pathways involving the differentially expressed lncRNAs; A stands for upregulated signaling pathways; B stands for downregulated signaling pathways.

found that VEGF and pSTAT3 were significantly upregulated following OGD/R. In contrast, the knockdown of Gpr137b-ps with a lentivrius decreased the expression of VEGF and pSTAT3 compared with transfection with a non-targeting Gpr137b-ps shRNA in vitro (Fig. 8A-8D). Therefore, the results were consistent with those of the bioinformatics analysis, and STAT3 and VEGF may be the target genes of Gpr137b-ps. 


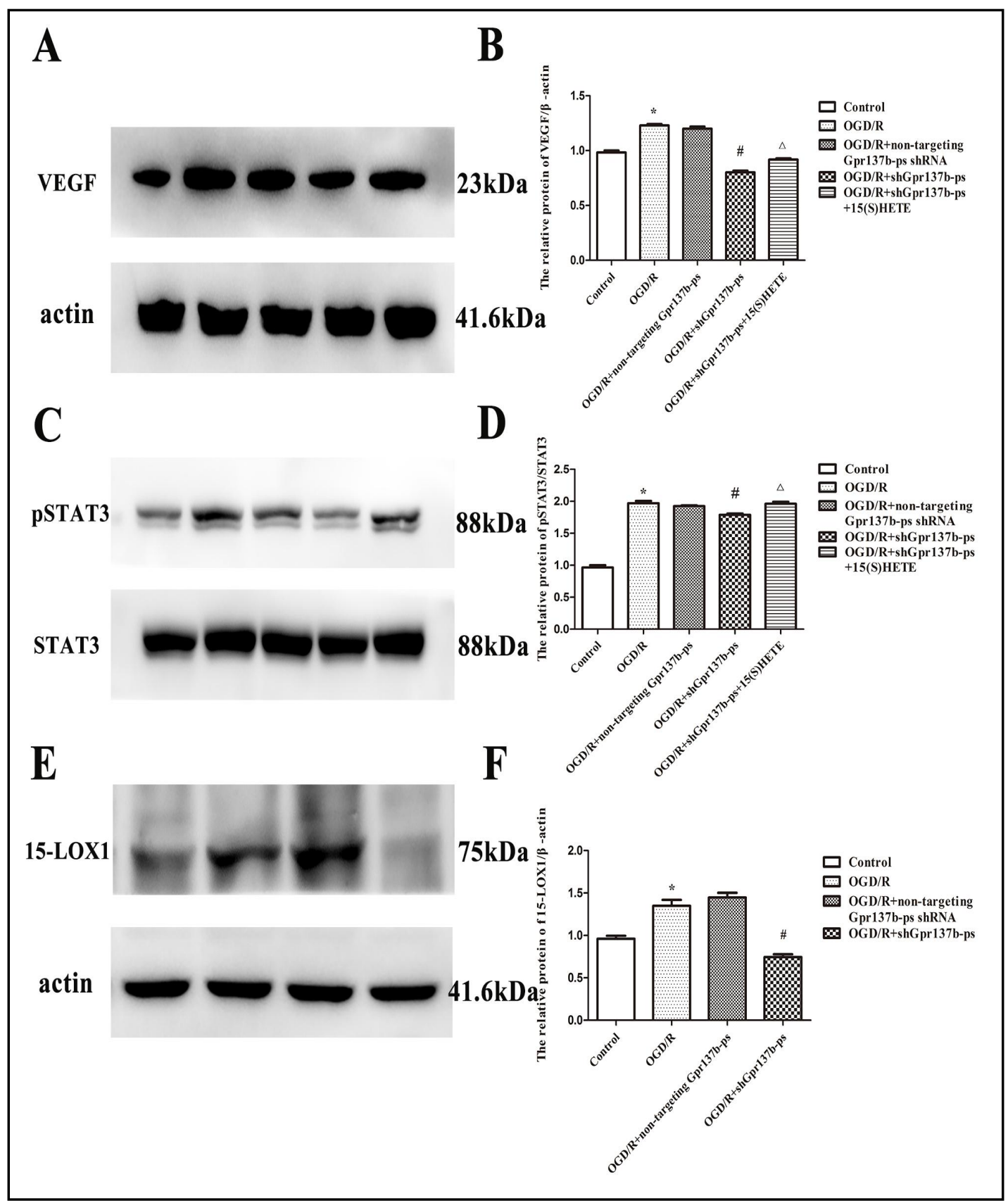

Fig. 8. The relative expression levels of VEGF, pSTAT3 and 15-LOX1 in vitro. (A-D) The protein levels of VEGF and pSTAT3 in cells exposed to control, OGD/R, OGD/R+ non-targeting Gpr137b-ps shRNA, OGD/ $\mathrm{R}+$ shGpr137b-ps, and OGD/R+ shGpr137b-ps with 15(S)-HETE. (E-F) The protein levels of 15-LOX1 in cells exposed to control, OGD/R, OGD/R+non-targeting Gpr137b-ps shRNA and OGD/R+shGpr137b-ps ${ }^{*} \mathrm{p}$ $<0.05$ OGD/R vs control, \# p <0.05 OGD/R+shGpr137b-ps vs OGD/R+ non-targeting Gpr137b-ps shRNA, $\triangle$ $\mathrm{p}<0.001$ OGD/R+shGpr137b-ps $+15(\mathrm{~S})$-HETE vs. OGD/R+shGpr137b-ps). All results are presented as the mean \pm SEM.

\section{Gpr137b-ps regulates the expression of STAT3 and VEGF via 15-LOX1}

In previous studies, there was a close relationship between 15-lipoxygenase 1 (15LOX1) and STAT3 in both VSMCs (vascular smooth muscle cells, VSMCs) and pulmonary artery endothelial cells, indicating that 15-LOX1 production can induce STAT3 tyrosine 


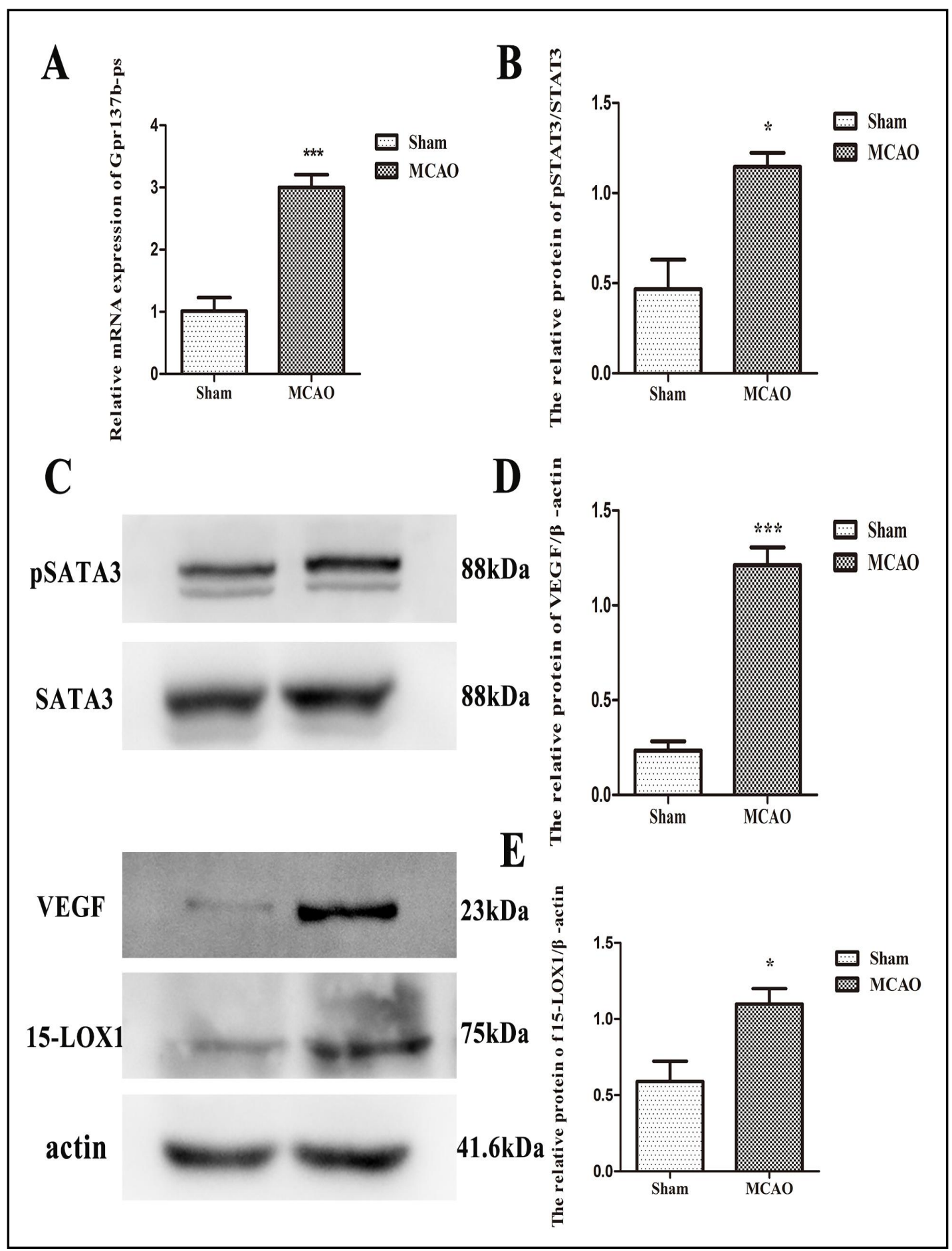

Fig. 9. The validation of Gpr137b-ps, VEGF, pSTAT3 and 15-LOX1 in vivo. (A) The relative mRNA expression of Gpr137b-ps after MCAO. (B-E) The protein levels of VEGF, pSTAT3 and 15-LOX1 in the sham and MCAO groups $\left({ }^{*} \mathrm{p}<0.05,{ }^{* *} \mathrm{p}<0.01,{ }^{* * *} \mathrm{p}<0.001\right.$ vs control). All results are presented as the mean $\pm \mathrm{SEM}$.

phosphorylation [30]. Thus, we hypothesized that 15-LOX1 may be an upstream factor affecting STAT3 in angiogenesis following OGD/R. In our studies, 15-LOX1 levels were analysed in the control group, OGD/R group, OGD/R+non-targeting Gpr137b-ps shRNA group, and OGD/R+shGpr137b-ps group. We found that the expression of 15-LOX1 presented the same trend as that of Gpr137b-ps (Fig. 8E, 8F). Subsequently, to confirm whether 15- 
LOX1 was responsible for the effects of Gpr137b-ps on STAT3 and VEGF, exogenous 15-HETE $(1 \mu \mathrm{mol} / \mathrm{mL})$ was found to attenuate the decrease in cell tube formation mediated by 15-LO siRNA, as observed in our previous studies [31]. As a result, we employed exogenous 15(S)HETE (Cayman, Ellsworth, USA) and found that it could counteract the effect of shGpr137bps on the expression of VEGF and pSTAT3 (Fig. 8A-8D).

The expression of Gpr137b-ps, VEGF, pSTAT3 and 15-LOX1 in mice after MCAO

To extend our in vitro observations into in vivo studies, we further detected whether Gpr137b-ps and its targets had similar expression trends in mice after middle cerebral artery occlusion. Total RNA and protein were isolated and subjected to detection of the mRNA level of Grp137b-ps and the relative protein levels of VEGF, pSTAT3 and 15-LOX1. As expected, Gpr137b-ps, VEGF, pSTAT3 and 15-LOX1 were also significantly upregulated in response to cerebral ischemia (Fig. 9A-E).

\section{PPI analysis of $m R N A s$}

For species with annotated information in the protein-protein interaction database, we also analysed the PPI network of the differentially expressed genes. The interaction data obtained from the STRING database were imported into Cytoscape to generate the visual representation of the PPI network. The PPI network analysis of the differentially expressed mRNAs, including the upregulated mRNAs and downregulated mRNAs is shown in Supplementary Fig. 3A, 3C, 3E. Moreover, some clusters were analysed with MCODE in every network according to the score and nodes, and the top MCODE value was shown in all, up and down regulated mRNA (Supplementary Fig. 3B, 3D, 3F).

\section{Discussion}

Endothelial cell proliferation, migration and sprouting are tightly coordinated processes mediating the formation of new vessels during physiological and pathological angiogenesis [32-34], and are intricately regulated by various signaling pathways [35, 36]. Therefore, it is crucial to explore the precise mechanisms and novel therapeutic targets of EC proliferation, migration, tube formation and increased of microvascular density after ischemic stroke, which promote clinical angiogenesis in patients.

LncRNAs have long been considered to be nonfunctional relics littering the genome, but increasing evidence has demonstrated that lncRNAs are important factors in cell biology [37]. To date, IncRNAs dysregulation has been shown to mediate diverse human diseases, including ischemic stroke and cancer [38]. Based on the structure and function of lncRNAs, they are further subdivided into long intergenic ncRNAs, long intronic ncRNAs, telomeric ncRNAs, pseudogenes, enhancer RNAs, circRNAs and promoter-associated long RNAs [39, 40]. Pseudogenes, non-coding RNA homologs of protein-coding genes, have been shown to function as regulators of gene expression [41]. Recent studies have also highlighted the functional roles of pseudogenes in physiological and pathological processes, including cell differentiation, proliferation, apoptosis and migration [42-44]. In particular, it was reported that they may be crucial regulators of the development and progression of cancer [45, 46]. In addition, some evidence has revealed that certain pseudogenes, such as stroke-responsive IncRNAs, might also restore protein synthesis and control chromatin modifications, transcription factor activity and apoptosis [47, 48]. However, the number of reports illuminating the roles of pseudogenes in ECs after ischemic stroke is still limited. Thus, the potential functional roles and mechanisms of action of pseudogene-derived lncRNA after stroke needs further study to identify therapeutic targets in ischemic stroke patients.

With the development of high-throughput sequencing, increasingly thorough analysis of whole genomes has been possible. In our study, we evaluated angiogenesis-associated IncRNAs in both OGD/R and control ECs using RNA-seq. There were 2710 lncRNAs (1306 annotated and 1404 non-annotated) detected, 33 of which were significantly differentially 
expressed. In particular, Gpr137b-ps was significantly upregulated in the OGD/R group compared with the control group. Furthermore, the increase in the expression of Gpr137bps was also validated by qRT-PCR. The qRT-PCR results were consistent with the predicted results of the RNA sequencing. Consequently, these findings are the first to show that OGD/R influences Gpr137b-ps expression in ECs. Next, we explored the significant functional roles of Gpr137b-ps in cerebrovascular endothelial cells after OGD/R. The proliferation, migration and tube formation of ECs are important processes during EC angiogenesis. Here, we described a role for Gpr137b-ps in promoting angiogenesis, which was supported by the results of the cell survival, migration, transwell, tube formation and immunofluorescence assays. Gpr137b-ps transfected with the lentivirus inhibited EC proliferation, migration and tube formation and reduced the number of CD31-positive microvascular ECs. Taken together, our results suggested that Gpr137b-ps could promote EC proliferation, migration and neovascularization. Therefore, our findings implied that the pseudogene-derived lncRNA Gpr137b-ps might exert critical positive effects on the progression of angiogenesis following OGD/R. However, as a novel proangiogenic gene, the mechanisms by which Gr137b-ps mediates angiogenesis have not yet been reported.

To further explore the potential mechanisms by which angiogenesis is induced by Gpr137b-ps, all targets were included in the GO term and KEGG pathway enrichment analyses that were conducted with the GOseq R package. The results obtained from the GO and KEGG enrichment analyses may provide insight into the function and associated cell pathways of differentially expressed IncRNAs. Therefore, based on the GO and KEGG analyses, we found several potential target genes of Gpr137b-ps, such as interleukin 6 (IL6), STAT3, epidermal growth factor (EGF), Akt3 and VEGF. Among them, VEGF represents a validated therapeutic target for neovascular disorders [49], and endothelial cell-derived VEGF promotes EC proliferation, migration and angiogenesis [50]. It has been demonstrated that VEGF expression is upregulated in the ischemic penumbra regions within $3 \mathrm{~h}$ following the onset of acute ischemia [51]. Furthermore, increasing evidence has demonstrated that VEGF gene transcription occurs situated downstream of STAT3 [52]. In the present study, we found that the expression levels of pSTAT3 and VEGF were positively related to the regulation of Gpr137b-ps. Therefore, our findings indicate that Gpr137b-ps may not only give rise to angiogenesis in response to hypoxic stimulation in ECs, but may also promote angiogenesis by regulating STAT3 and VEGF expression.

The expression of 15-LOX1, another signal transducing factor, was increased in pulmonary adventitial fibroblasts and mediated adventitia remodeling in response to hypoxia, similar to VEGF. Furthermore, increasing evidence has suggested that 15-LOX1 could induce VEGF expression and angiogenesis in cancer [53]. In this study, we also observed that the regulation of 15-LOX1 was consistent with that of Gpr137b-ps. Thus, we speculated that Gpr137b-ps might regulate angiogenesis via 15-LOX1, STAT3 and VEGF. To confirm our hypothesis, the expression of Gpr137b-ps was reduced in ECs via lentiviruses. Then, we found that the increase in 15-LOX1, pSTAT3 and VEGF at the protein level was reversed after the knockdown of Gpr137b-ps. These findings suggest that the differential expression of 15LOX1, STAT3 and VEGF may be caused by the differential expression of Gpr137b-ps. Moreover, the mimics of 15-LOX1 counteracted the anti-angiogenic effect mediated by shGpr137b-ps, as revealed by analysing the expression of downstream genes, including pSTAT3 and VEGF. STAT3 is an upstream gene of VEGF according to our previous study. Taken together, our findings demonstrate that Gpr137b-ps may exert a proangiogenic role via the 15-LOX1/ STAT3/VEGF signaling pathway following OGD/R. It is clear that, except for regulating target gene expression via a signaling pathway, recent studies have shown that pseudogenes can regulate their parental transcripts by sequestering shared microRNAs (miRNAs), thus acting as competing endogenous RNAs (ceRNAs) [45]. A specific pseudogene homologous to the Makorin-1 gene can stable the transcription of Makorin-1 in bone deformities [25], and PTENP1 can sponge PTEN-targeting miRNAs and regulate cellular PTEN expression to exert a tumor-suppression effect [54]. In contrast, the knockdown of PTENP1 results in decreases in the mRNA and protein levels of PTEN, indicating that PTENP1 transcript 


\section{Cellular Physiology Cell Physiol Biochem 2019;52:708-727

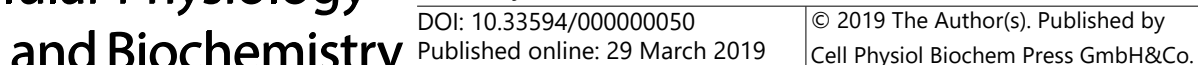 \\ Wang et al.: The Proaniogenic Roles of IncRNAs}

levels can regulate PTEN expression [47]. Based on the above studies, we propose a similar relationship between Gpr137b-ps and its homologous gene. Therefore, our attention will focus on this aspect in the future.

\section{Conclusion}

In summary, we uncovered for the first time that a novel pseudogene-expressed IncRNA Gpr137b-ps, is significantly upregulated after OGD/R, indicating that it mediates EC proliferation, migration, tube formation and the increase in CD31-positive ECs observed during angiogenesis via the 15-LOX1/STAT3/VEGF signaling pathway. In general, our study not only provides a new prospective on molecular targets for post-stroke pro-angiogenic treatment but also indicates the potential mechanism by which Gpr137b-ps mediates angiogenesis. However, the exact mechanism by which Gpr137b-ps regulates miRNAs during post-stroke angiogenesis is still not fully understood and will be addressed in future work.

\section{Acknowledgements}

The authors greatly appreciate the comments provided by the editors and peer reviewers.

\section{Disclosure Statement}

The authors declare that they have no conflicts of interest.

\section{References}

- 1 Lai SM, Alter M, Friday G, Sobel E: A multifactorial analysis of risk factors for recurrence of ischemic stroke. Stroke 1994;25:958-962.

2 Ergul A, Alhusban A, Fagan SC: Angiogenesis: a harmonized target for recovery after stroke. Stroke 2012;43:2270-2274.

3 Yin KJ, Milton HY, Chen E: Angiogenesis-regualting microRNAs and ischemic stroke. Curr Vas Pharmacol 2015;13:352-365.

4 Folkman J: Seminars in medicine of the beth israel hospital, Boston. Clinical applications of research on angiogenesis. N Engl J Med 1995;333:1757-1763.

- 5 Boulberdaa M, Scott E, Ballantyne M, Garcia R, Descamps B, Angelini GD, Brittan M, Hunter A, McBride M, McClure J, Miano JM, Emanueli C, Mills NL, Mountford JC, Baker AH: A role for the long noncoding RNA SENCR in commitment and function of endothelial cells. Mol Ther 2016;24:978-990.

- 6 Cheng J, Kaparanov P, Drenkow J, Dike S, Brubaker S, Patel S, Long J, Stern D, Tammana H, Helt G, Sementchenko V, Piccolboni A, Bekiranov S, Bailey DK, Ganesh M, Ghosh S, Bell I, Gerhard DS, Gingeras TR: Transcriptional maps of 10 human chromosomes at 5-nucleotide resolution. Science 2005;308:1149-1154.

- 7 Gutschner T, Diederichs S: The hallmarks of cancer: a long non-coding RNA point of view. RNA Biol 2012;9:703-719.

- 8 Ashutosh D, Venkata PN, Raghu V: Effect of focal ischemia on long noncoding RNAs. Stroke 2012;43:28002802.

- 9 Jacq C, Miller JR, Brownlee GG: A pseudogene structure in 5S DNA of Xenopus laevis. Cell 1977;12:109-120.

- 10 Groen JN, Capraro D, Morris KV: The emerging role of pseudogene expressed non-coding RNAs in cellular functions. Int J Biochem Cell Biol 2014;54:350-355.

11 Li XJ, Gao AM, Ji LJ, Xu J: Pseudogene in cancer: real functions and promising signature. J Med Genet 2015;52:17-24. 


\section{Cellular Physiology Cell Physiol Biochem 2019;52:708-727 \begin{tabular}{ll|l|l} 
DOI: 10.33594/000000050 & O 2019 The Author(s). Published by \\
\hline
\end{tabular} and Biochemistry Published online: 29 March 2019 Cell Physiol Biochem Press GmbH\&Co. KG \\ Wang et al.: The Proaniogenic Roles of IncRNAs}

- 12 Kalyana-Sundaram S, Kumar-Sinha C, Shankar S, Robinson DR, Wu YM, Cao X, Asangani IA, Kothari V, Prensner JR, Lonigro RJ, Iyer MK, Barrette T, Shanmugam A, Dhanasekaran SM, Palanisamy N, Chinnaiyan AM: Expressed pseudogenes in the transcriptional landscape of human cancers. Cell 2012;149:1622-1634. Goodhead I, Darby AC: Taking the pseudo out of pseudogenes. Curr Opin Microbiol 2015;23:102-109. Jingsi T, Mingyao Y, Ying L: Functional roles of pseudogenes in cancers. Yi Chuan 2015;37:8-16.

15 Li W, Yang W, Wang XJ: Pseudogenes: Pseudo or Real Functional Elements? J Genet Genomics 2013;40:171177.

16 Hayashi H, Arao T, Togashi Y, Kato H, Fujita Y, De Velasco MA, Kimura H, Matsumoto K, Tanaka K, Okamoto I, Ito A, Yamada Y, Nakagawa K, Nishio K: The OCT4 pseudogene POU5F1B is amplified and promotes an aggressive phenotype in gastric cancer. Oncogene 2015;34:199-208.

- 17 Mei D, Song H, Wang K, Lou Y, Sun W, Liu Z, Ding X, Guo J: Up-regulation of SUMO1 pseudogene 3 (SUM01P3) in gastric cancer and its clinical association. Med Oncol 2013;30:709. Langmead B, Salzberg SL: Fast gapped-read alignment with Bowtie 2. Nat Methods 2012;9:357-359. Trapnell C, Willianms BA, Pertea G., Mortazavi A, Kwan G, van Baren MJ, Salzberg SL, Wold BJ, Pachter L: Transcript assembly and quantification by RNA-seq reveals unannotated transcripts and isoform switching during cell differentiation. Nat Biotechnol 2010;28:511-515.

20 Hansen KD, Irizarry RA, Wu ZJ: Removing technical variability in RNA-seq data using conditional quantile normalization. Biostatistics 2012;13:204-216.

21 Sun L, Luo H, Bu D, Zhao G, Yu K, Zhang C, Liu Y, Chen R, Zhao Y: Utilizing sequence intrinsic composition to classify protein-coding and long non-coding transcripts. Nucleic Acids Res 2013;41:66.

22 Kong L, Zhang Y, ZQ Ye, Liu XQ Zhao SQ, Wei L, Gao G: CPC: assess the protein-coding.potential of transcripts using sequence features and support vector machine. Nucleic Acids Res 2007;36:W345-349.

23 Punta M, Coggill PC, Eberhardt RY, Mistry J, Tate J, Boursnell C, Pang N, Forslund K, Ceric G, Clements J, Heger A, Holm L, Sonnhammer EL, Eddy SR, Bateman A, Finn RD: The Pfam protein families database. Nucleic Acids Res 2012;40:D290-301.

24 Lin MF, Jungreis I, Kellis M: PhyloCSF: a comparative genomics method to distinguish protein coding and non-coding regions. Bioinformatics 2011;27:275-282.

25 Gupta RA, Shah N, Wang KC, Kim J, Horlings HM, Wong DJ, Tsai MC, Hung T, Argani P, Rinn JL, Wang Y, Brzoska P, Kong B, Li R, West RB, van de Vijver MJ, Sukumar S, Chang HY: Long non-coding RNA hotair reprograms chromatin state to promote cancer metastasis. Nature 2010;464:1071-1076.

26 Young MD, Wakefield MJ, Smyth G.K, Oshlack A: Gene ontology analysis for RNA-seq: accounting for selection bias. Genome Biol 2010;11:14.

27 Kanehisa M, Araki M, Goto S, Hattori M, Hirakawa M, Itoh M, Katayama T, Kawashima S, Okuda S, Tokimatsu T, Yamanishi Y: KEGG for linking genomes to life and the environment. Nucleic Acids Res 2008;36:480-484. Mao X, Cai T, Olyarchuk JG, Wei L: Automated genome annotation and pathway identification using the KEGG Orthology (KO) as a controlled vocabulary. Bioinformatics 1995;21:3787-3793.

29 Schonrock N, Harvey RP, Mattick JS: Long noncoding RNAs in cardiac development and pathophysiology. Circ Res 2012;111:1349-1362.

30 Kovacic JC, Gupta R, Lee AC, Ma M, Fang F, Tolbert CN, Walts AD, Beltran LE, San H, Chen G, St Hilaire C, Boehm M: Stat3-depedent acute rantes production in vascular smooth muscle cells modulates inflammation following arterial injury in mice. J Clin Invest 2010;120:303-314.

31 Wang D, Liu Y, Chen L, Li PY, Qu YY, Zhu YM, Zhu YL: Key role of 15-LO/15-HETE in angiogenesis and functional recovery in later stages of post-stroke mice. Sci Rep 2017;7:46698.

32 Mara EP, Inga S, Benedetto DG, Tobian A, Frank B, Feancesca F, Hongryeol P, Manuel E, Daniel B, Susana FR, Urs HL, Martin S, Takashi N, Napoleone F, Tilman B: Dll4 and Notch signalling couples sprouting angiogenesis and artery formation. Nat Cell Biol 2017;5:1-8.

33 Yla-Herttuala S, Rissanen TT, Vajanto I, Hartikainen J: Vascular endothelial growth factors: biology and current status of clinical applications in cardiovascular medicine. J Am Coll Cardiol 2007;49:1015-1026.

34 Zhao T, Zhao W, Chen Y, Ahokas RA, Sun Y: Vascularendothelial growth factor (VEGF)-A: role on cardiac angiogenesis following myocardial infarction. Microvasc Res 2010;80:188-194.

35 Coultas L, Chawengsaksophak K, Rossant J: Endothelial cells and VEGF in vascular development. Nature $8002005 ; 48: 937-945$. 


\section{Cellular Physiology Cell Physiol Biochem 2019;52:708-727 \begin{tabular}{ll|l|l} 
DOI: 10.33594/000000050 & O 2019 The Author(s). Published by \\
\hline
\end{tabular} and BiOChemistry Published online: 29 March 2019 Cell Physiol Biochem Press GmbH\&Co. KG \\ Wang et al.: The Proaniogenic Roles of IncRNAs}

36 Liang L, Yue Z, Du W, Li Y, Tao H, Wang D, Wang R, Huang Z, He N, Xie X, Han Z, Liu N, Li Z: Molecular imaging of inducible VEGF expression and tumor progression in a breast cancer model. Cell Physiol Biochem 2017;42:407-415.

- 37 Qureshi IA, Mehler MF: Long non-coding RNAs: novel targets for nervous system disease diagnosis and therapy. Neurotherapeutics 2013;10:632-646.

- 38 Zhang K, Sun X, Zhou X, Han L, Chen L, Shi Z, Zhang A, Ye M, Wang Q, Liu C, Wei J, Ren Y, Yang J, Zhang J, Pu P, Li M, Kang C: Long non-coding RNA HOTAIR promotes glioblastoma cell cycle progression in an EZH2 dependent manner. Oncotarget 2015;6:537-546.

- 39 Vemuganti R: All's well that transcribes well: non-coding RNAs and post-stroke brain damage. Neurochem Int 2013;63:438-449.

40 Schonrock N, Harvey RP, Mattick JS: Long noncoding RNAs in cardiac development and pathophysiology. Circ Res 2012;111:1349-1362.

41 Hawkins PG, Morris KV: Transcriptional regulation of Oct4 by a long non-coding RNA antisense to Oct4pseudogene 5. Transcription 2010;1:165-175.

42 Zhou M, Wang X, Shi H, Cheng L, Wang Z, Zhao H, Yang L, Sun J: Characterization of long non-coding RNAassociated ceRNA network to reveal potential prognostic lncRNA biomarkers in human ovarian cancer. Oncotarget 2016;7:12598-12611.

- 43 Huang JL, Ren TY, Cao SW, Zheng SH, Hu XM, Hu YW, Lin L, Chen J, Zheng L, Wang Q: HBx-related long non-coding RNA DBH-AS1 promotes cell proliferation and survival by activating MAPK signaling in hepatocellular carcinoma. Oncotarget 2015;6:33791-33804.

- 44 Zhou M, Xu W, Yue X, Zhao H, Wang Z, Shi H, Cheng L, Sun J: Relapse-related long non-coding RNA signature to improve prognosis prediction of lung adenocarcinoma. Oncotarget 2016;7:29720-29738.

- 45 Hirotsune S, Yoshida N, Chen A, Garrett L, Sugiyama F, Takahashi S, Yagami K, Wynshaw-Boris A, Yoshiki A: An expressed pseudogene regulates the messenger-RNA stability of its homologous coding gene. Nature 2003;423:91-96.

46 Pink RC, Wicks K, Caley DP, Punch EK, Jacobs L, Francisco Carter DR: Pseudogenes: Pseudo-functional or key regulators in health and disease? RNA 2011;17:792-798.

47 Huarte M, Guttman M, Feldser D, Garber M, Koziol MJ, Kenzelmann-Broz D, Khalil AM, Zuk O, Amit I, Rabani M, Attardi LD, Regev A, Lander ES, Jacks T, Rinn JL: A large intergenic noncoding RNA induced by p53 mediates global gene repression in the 53 response. Cell 2010;142:409-419.

48 Khalil AM, Guttman M, Huarte M, Garber M, Raj A, Rivea Morales D, Thomas K, Presser A, Bernstein BE, van Oudenaarden A, Regev A, Lander ES, Rinn JL: Many human large intergenic 832 noncoding RNAs associate with chromatin-modifying complexes and affect gene expression. Proc Natl Acad Sci 2009;106:1166711672.

- 49 Ferrara N, Adamis AP: Ten years of anti-vascular endothelial growth factor therapy. Nat Rev Drug Discov 2016;15:385-403.

50 E G, Cao Y, Bhattacharya S, Dutta S, Wang EF, Mukhopadhyay D: Endogenous vascular endothelial growth factor-A (VEGF-A) maintains endothelial cell homeostasis by regulating VEGF receptor-2 transcription. J Biol Chem 2012;287:3029-3041.

- 51 Hayashi T, Abe K, Suzuki H, Itoyama Y: Rapid induction of vascular endothelial growth factor gene expression after transient middle cerebral artery occlusion in rats. Stroke 1997;28:2039-2044.

52 Pages G, Pouyssegur J: Transcriptional regulation of the Vascular Endothelial Growth Factor gene - a concert of activating factors. Cardiovasc Res 2005;65:564-573.

53 Srivastava K, Kundumani-Sridharan V, Zhang B, Bajpai AK, Rao GN: 15(S)-hydroxyeicosatetraenoic acidinduced angiogenesis requires STAT3-dependent expression of VEGF. Cancer Res 2007;67:4328-4336.

54 Poliseno L, Salmena L, Zhang J, Carver B, Haveman WJ, Pandolfi PP: A coding-independent function of gene and pseudogene mRNAs regulates tumour biology. Nature 2010;465:1033-1038. 